in MS patients, working together with neurologists, to prevent the appearance of fractures and protect the quality of life of these patients. An analysis of our whole cohort of MS patients will help us in correctly assessing the magnitude of this problem.

REFERENCES:

[1] López Méndez P, Sosa Henríquez M. Vitamin D and multiple sclerosis. Prevalence of hypovitaminosis D. Rev Osteoporos y Metab Miner. 2015;7(2):71-78.

[2] Gupta S, Ahsan I, Mahfooz N, Abdelhamid N, Ramanathan M, Weinstock-Guttman B. Osteoporosis and multiple sclerosis: Risk factors, pathophysiology, and therapeutic interventions. CNS Drugs. 2014;28(8):731-742.

[3] Moen S, E.Celius, L S, L N, E E, T H. Low bone mass in newly diagnosed multiple sclerosis and clinically isolated syndrome. Neurology. 2011;77(2):151-157.

[4] Lems WF, Dreinhöfer KE, Bischoff-Ferrari $\mathrm{H}$, et al. EULAR/EFORT recommendations for management of patients older than 50 years with a fragility fracture and prevention of subsequent fractures. Ann Rheum Dis. 2017;76(5):802-810.

Disclosure of Interests: None declared

DOI: 10.1136/annrheumdis-2021-eular.3214

\section{POS0169 FETUIN-A AS A MARKER OF OSTEOPOROSIS AND OSTEOPOROTIC FRACTURES IN PATIENTS WITH RHEUMATOID ARTHRITIS}

Y. Akhverdyan ${ }^{1}$, E. Papichev ${ }^{1}$, B. Zavodovsky ${ }^{1}$, L. Seewordova ${ }^{1}$, J. Polyakova ${ }^{1}$. ${ }^{1}$ Federal State Budgetary Institution «Research Institute of Clinical and Experimental Rheumatology Named After A.B. Zborovsky», Joint Diseases Treatment and Prevention Laboratory, Volgograd, Russian Federation

Background: The main mechanism of the effect of fetuin- $\mathrm{A}(\mathrm{FeA})$ on bone metabolism is its ability to bind calcium and proteins of the TGF- $\beta$ family. It has been proven that the optimal concentration of TGF- $\beta$ is necessary for the differentiation of bone tissue, and a high concentration inhibits bone mineralization. Thus, adequate osteogenesis is based on a complex balance between FeA and TGF- $\beta$ levels. It can be assumed that the determination of the FeA level in the blood of patients with rheumatoid arthritis (RA) will help to optimize the diagnosis and predict the severity of osteoporosis (OP).

Objectives: to study the possibility of predicting the development of osteoporosis and osteoporetic fractures in patients with $\mathrm{RA}$, depending on the level of $\mathrm{FeA}$ in blood serum.

Methods: We examined two groups of patients (52 patients with RA complicated by OP, 58 patients with RA without OP) and 30 apparently healthy individuals. The age of the surveyed ranged from 18 to 72 years, the average duration of the disease was $7.53 \pm 0.89$ years. In both groups, the FeA level was determined by an indirect enzyme-linked immunosorbent assay using a commercial test. Bone mineral density (BMD) was also measured in both groups (Lunar DPX-NT GE).

Results: The average FeA level in the group of RA patients was lower than in the group of conventionally healthy individuals $(731.21 \pm 109.9 \mu \mathrm{g} / \mathrm{ml}$ and $812.9 \pm 76.2$ $\mu \mathrm{g} / \mathrm{ml}$, respectively; $\mathrm{F}=13.34 ; \mathrm{p}=0,0004)$. The normal FeA level was calculated using the formula $\mathrm{M} \pm 2 \sigma$ in the group of apparently healthy individuals and ranged from $653.55 \mu \mathrm{g} / \mathrm{ml}$ to $972.19 \mu \mathrm{g} / \mathrm{ml}$.

A decreased level of FeA was found in 20 patients $(86.96 \%)$ in the group of patients with OP and only in $3(13.04 \%)$ patients with RA who did not suffer from OP $(p<0.001)$. It can be concluded that patients with RA and a low concentration of $\mathrm{FeA}$ in the blood serum have a higher risk of developing OP.

In the group of patients with normal FeA level, osteoporetic fractures were observed in $12(13.79 \%)$ patients and were absent in $75(86.21 \%)$ patients $(p<0.001)$. Thus, RA patients with normal serum FeA levels have a lower risk of osteoporetic fractures.

We also found a positive significant correlation between the level of FeA and $\mathrm{BMD}$ in the femoral neck area. In the group of patients with a reduced FeA level (23 people), the mean BMD values were $0.732 \pm 0.022 \mathrm{~g} / \mathrm{cm} 2$, and in the group of patients with a normal FeA level (87 patients) $-0.890 \pm 0.014 \mathrm{~g} / \mathrm{cm} 2(p<0.001$, $\mathrm{F}=27.663$ ). The obtained values are in agreement with the literature data on the effect of the serum FeA concentration on the BMD values.

Conclusion: We consider it expedient to determine the serum FeA concentration in patients with RA. At a FeA level of $653.55 \mu \mathrm{g} / \mathrm{ml}$ and below, a higher risk of developing OP and osteoporetic fractures can be predicted. In this case, the patient is shown a standard examination for osteoporosis. At values of 653.55 $\mu \mathrm{g} / \mathrm{ml}$ and above, a more expectant management of the patient is allowed. Thus, by determining the serum concentration of $\mathrm{FeA}$, it is possible to implement an integrated approach to the patient and to optimize the schemes for the diagnosis of OP in patients with RA.
Disclosure of Interests: None declared

DOI: 10.1136/annrheumdis-2021-eular.753

\section{POS0170 IMPROVING MANAGEMENT OF GLUCOCORTICOID INDUCED OSTEOPOROSIS IN RHEUMATOLOGY}

A. Bankole ${ }^{1}, \underline{\text { S. Pachigolla }}{ }^{2} .^{1}$ Virginia Tech Carilion School of

Medicine, Medicine, Roanoke, United States of America; ${ }^{2}$ Carilion

Roanoke Memorial Hospital, Internal Medicine, Roanoke, United States of America

Background: Glucocorticoids (GC) are used in the treatment of various inflammatory conditions and it is estimated that about $1 \%$ of US population is treated with long term steroids. High doses of GC particularly those used by rheumatologists have adverse effects on bone health and is associated with rapid bone loss resulting in Glucocorticoid induced Osteoporosis(GIO) and an increased risk of fractures. The risk of bone loss relates to high daily dose and the high cumulative dose of the GC.

Despite the availability of effective preventative and treatment options, GIO is often under treated with many patients treated only after a fracture has occurred.

Objectives: The purpose of this study was to examine if providing education to care providers lead to an improvement in the identification, evaluation, and treatment of GIO.

Methods: This is a single center, prospective study that was performed at a university based tertiary referral center. Patients over 40 years, receiving a total cumulative dose of $\mathrm{GC}$ of $>5$ grams and/or a single dose of $>30 \mathrm{mg}$ of prednisone or equivalent was enrolled. A patient list was generated by our technology group. All providers received intervention in the form of an academic Journal Club, at which the current ACR guidelines regarding GIO was reviewed. Monthly reminders were shared with all providers within our monthly communications.

All the pre and post interventional data was analyzed. The continuous variables were analyzed using T-test or Mann-Whitney $U$ test. Categorical variables were analyzed using Chi-square Tests or Fisher's exact tests. Statistical analysis was performed using SAS9.4, and $p$ value $<0.05$ was considered statistically significant.

Results: Post education, there was a statistically significant increase in vitamin D replacement and the use of bisphosphonates as well as a reduction in the use of bone mineral density (BMD) tests within the at risk group while on $\mathrm{GC}$

Table 1. Glucocorticoid induced Osteoporosis (GIO)

\begin{tabular}{|c|c|c|c|}
\hline & $\begin{array}{l}\text { Pre-treatment } \\
\qquad(\mathrm{N}=72)\end{array}$ & $\begin{array}{l}\text { Post-treatment } \\
\qquad(\mathrm{N}=54)\end{array}$ & $\mathrm{p}$-value \\
\hline \multicolumn{4}{|l|}{ Demographics } \\
\hline Age (years) & $58.9 \pm 19.2$ & $64.2 \pm 16.7$ & 0.11 \\
\hline Body Mass Index & $29.0 \pm 6.7$ & $29.4 \pm 8.4$ & 0.77 \\
\hline Gender (Female) & $73.6 \%$ & $74.1 \%$ & 0.95 \\
\hline \multicolumn{4}{|l|}{ Race } \\
\hline White & $83.3 \%$ & $77.8 \%$ & 0.43 \\
\hline Hispanic & $1.4 \%$ & $5.6 \%$ & 0.31 \\
\hline \multicolumn{4}{|l|}{ Insurance } \\
\hline ANTHEM BCBS & $16.9 \%$ & $26.9 \%$ & \\
\hline Commercial & $11.3 \%$ & $11.5 \%$ & \\
\hline Medicaid & $12.7 \%$ & $9.6 \%$ & \\
\hline \multirow[t]{2}{*}{ Medicare } & $59.2 \%$ & $51.9 \%$ & \\
\hline & \multicolumn{3}{|c|}{ Medical History } \\
\hline Osteoporosis & $68.1 \%$ & $64.8 \%$ & 0.70 \\
\hline Osteoporotic Fracture & $15.3 \%$ & $11.1 \%$ & 0.50 \\
\hline Vasculitis & $26.4 \%$ & $22.2 \%$ & 0.59 \\
\hline Systemic Lupus Erythematosus & $18.1 \%$ & $13.0 \%$ & 0.44 \\
\hline Rheumatoid Arthritis & $12.5 \%$ & $25.9 \%$ & 0.05 \\
\hline Polymyalgia Rheumatica & $6.9 \%$ & $11.1 \%$ & 0.41 \\
\hline Inflammatory Muscle Disease & $18.1 \%$ & $20.4 \%$ & 0.74 \\
\hline Spondyloarthritis & $1.4 \%$ & $1.9 \%$ & 0.99 \\
\hline \multicolumn{4}{|l|}{ Lab Results } \\
\hline Serum Vitamin D (Normal) & $41.3 \%(19 / 46)$ & $52.8 \%(19 / 36)$ & 0.3 \\
\hline \multicolumn{4}{|l|}{ GIO Prevention Measures } \\
\hline Calcium & $2.8 \%$ & $13.0 \%$ & 0.04 \\
\hline Vitamin D & $18.1 \%$ & $61.1 \%$ & $<0.01$ \\
\hline Bisphosphonates & $9.7 \%$ & $35.2 \%$ & $<0.01$ \\
\hline RANKL inhibitors & $4.2 \%$ & $11.1 \%$ & 0.17 \\
\hline Bone Mineral Density & $43.5 \%(10 / 23)$ & $10.5 \%(2 / 19)$ & 0.02 \\
\hline
\end{tabular}

